\title{
Distribution of Chromium Contamination and Microbial Activity in Soil Aggregates
}

\author{
Tetsu K. Tokunaga,* Jiamin Wan, Terry C. Hazen, Egbert Schwartz, Mary K. Firestone, Stephen R. Sutton, \\ Matthew Newville, Keith R. Olson, Antonio Lanzirotti, and William Rao
}

\begin{abstract}
Biogeochemical transformations of redox-sensitive chemicals in soils can be strongly transport-controlled and localized. This was tested through experiments on chromium diffusion and reduction in soil aggregates that were exposed to chromate solutions. Reduction of soluble $\operatorname{Cr}(\mathrm{VI})$ to insoluble $\mathrm{Cr}$ (III) occurred only within the surface layer of aggregates with higher available organic carbon and higher microbial respiration. Sharply terminated $\mathrm{Cr}$ diffusion fronts develop when the reduction rate increases rapidly with depth. The final state of such aggregates consists of a Cr-contaminated exterior, and an uncontaminated core, each having different microbial community compositions and activity. Microbial activity was significantly higher in the more reducing soils, while total microbial biomass was similar in all of the soils. The small fraction of $\mathrm{Cr}(\mathrm{VI})$ remaining unreduced resides along external surfaces of aggregates, leaving it potentially available to future transport down the soil profile. Using the Thiele modulus, $\mathrm{Cr}(\mathrm{VI})$ reduction in soil aggregates is shown to be diffusion rate- and reaction rate-limited in anaerobic and aerobic aggregates, respectively. Thus, spatially resolved chemical and microbiological measurements are necessary within anaerobic soil aggregates to characterize and predict the fate of $\mathrm{Cr}$ contamination. Typical methods of soil sampling and analyses that average over redox gradients within aggregates can erase important biogeochemical spatial relations necessary for understanding these environments.
\end{abstract}

$\mathrm{T}$ HE FATE OF METAL CONTAMINANTS in soils and sediments is controlled by interdependent influences of transport and biogeochemical reactions. Laboratory studies of biogeochemical processes are commonly conducted in well-mixed suspensions and solution cultures. Limitations in applying results of laboratory studies to field environments often relate to the fact that the subsurface contains a broad spectrum of interconnected microenvironments, while individual laboratory batch systems represent specific isolated microenvironments. Complex patterns of subsurface flow and transport caused by preferential pathways in soils (Fig. 1) require us to understand the nature of local variations in properties and processes, and limit understanding based on larger-scale averaging. The current gap between understanding of well-mixed batch systems and observations on very complex natural subsurface systems provides incentive to examine biogeochemical dynamics in systems of intermediate complexity, which include the critical characteristics and coupling of relevant microenvironments. Individual soil aggregates can contain wide

T.K. Tokunaga, J. Wan, T.C. Hazen, and K.R. Olson, Lawrence Berkeley National Laboratory, Berkeley, CA, 94720. E. Schwartz and M.K. Firestone, Univ. of California, Berkeley, CA 94720. S.R. Sutton, M. Newville, and A. Lanzirotti, Univ. of Chicago, Chicago, IL 60637. W. Rao, Savannah River Ecology Laboratory, Univ. of Georgia, Aiken, SC 29802. Received 6 June 2002. *Corresponding author (tktokunaga @lbl.gov).

Published in J. Environ. Qual. 32:541-549 (2003). variations in chemical (Wilcke and Kaupenjohann, 1998) and microbiological (Seech and Beauchamp, 1988; Drazkiewicz, 1994) composition, and sustain biogeochemical transformations through diffusion-controlled fluxes. Steep gradients in oxygen concentrations and redox potentials in soil aggregates that exhibit anaerobic interiors (Currie, 1961; Smith, 1977) indicate that transformations experienced by redox-sensitive metal contaminants can occur within short distances (Fig. 1). Thus, experiments on metal transformations within soil aggregates permit examination of interdependent effects of transport, microbial activity, and reactions under environmentally realistic conditions and well-defined geometry.

Chromium, used in a variety of industrial processes, has become a serious problem as a contaminant in soils (Proctor et al., 1997). Chromium(III) occurs in soil primarily as stable solids and strongly adsorbed species, while most $\mathrm{Cr}(\mathrm{VI})$ species are soluble and mobile (Rai et al., 1989). In uncontaminated soils, $\mathrm{Cr}$ is found as $\mathrm{Cr}(\mathrm{III})$ because of the high pe range associated with $\mathrm{Cr}(\mathrm{VI})-\mathrm{Cr}(\mathrm{III})$ transformations. Thus, high proportions of $\mathrm{Cr}(\mathrm{VI})$ are largely restricted to contaminated sites (Palmer and Wittbrodt, 1991; James, 1996). Some of these sites are heavily contaminated, with $\mathrm{Cr}(\mathrm{VI})$ concentrations in ground waters exceeding $1000 \mathrm{mg} \mathrm{L}^{-1}$ (Palmer and Wittbrodt, 1991; Makdisi, 1992; Sturges et al., 1992), yet few laboratory studies have been done to address the fate of such high levels of $\mathrm{Cr}(\mathrm{VI})$. The soil microbial community can promote $\mathrm{Cr}(\mathrm{VI})$ reduction to $\mathrm{Cr}(\mathrm{III})$ directly through enzymatic pathways (Lovley, 1993; Losi et al., 1994), and indirectly through depleting oxygen and releasing reductants such as ferrous iron, sulfide, and organic compounds (Lovley et al., 1991; Chapelle, 1992). Recent comparisons of abiotic versus enzymatic $\mathrm{Cr}(\mathrm{VI})$ reduction kinetics indicate that aqueous $\mathrm{Fe}(\mathrm{II})$ mediated reduction is expected to be dominant in neutral to alkaline anaerobic soils (Fendorf et al., 2000; Wielinga et al., 2001). Active microbial communities nevertheless exert dominant influences since they mediate the depletion of oxygen and the availability of reactive reductants $[\mathrm{Fe}(\mathrm{II})$ and $\mathrm{S}(-\mathrm{II})]$. Soil microbial communities are also influenced by exposure to high concentrations of $\mathrm{Cr}(\mathrm{VI})$, with responses including death, resistance development, and enzymatic reduction (Lovley, 1993; Losi and Frankenberger, 1994). Thus, interactions between soil microbial communities and invading $\mathrm{Cr}(\mathrm{VI})$ solutions are complex but central to the fate of the contaminant.

As noted earlier, aggregates are the smallest systems within soils in which wide ranges of biogeochemical interactions can be coupled, with well-defined spatial relations. However, intra-aggregate heterogeneity might

Abbreviations: XANES, X-ray absorption near-edge structure. 


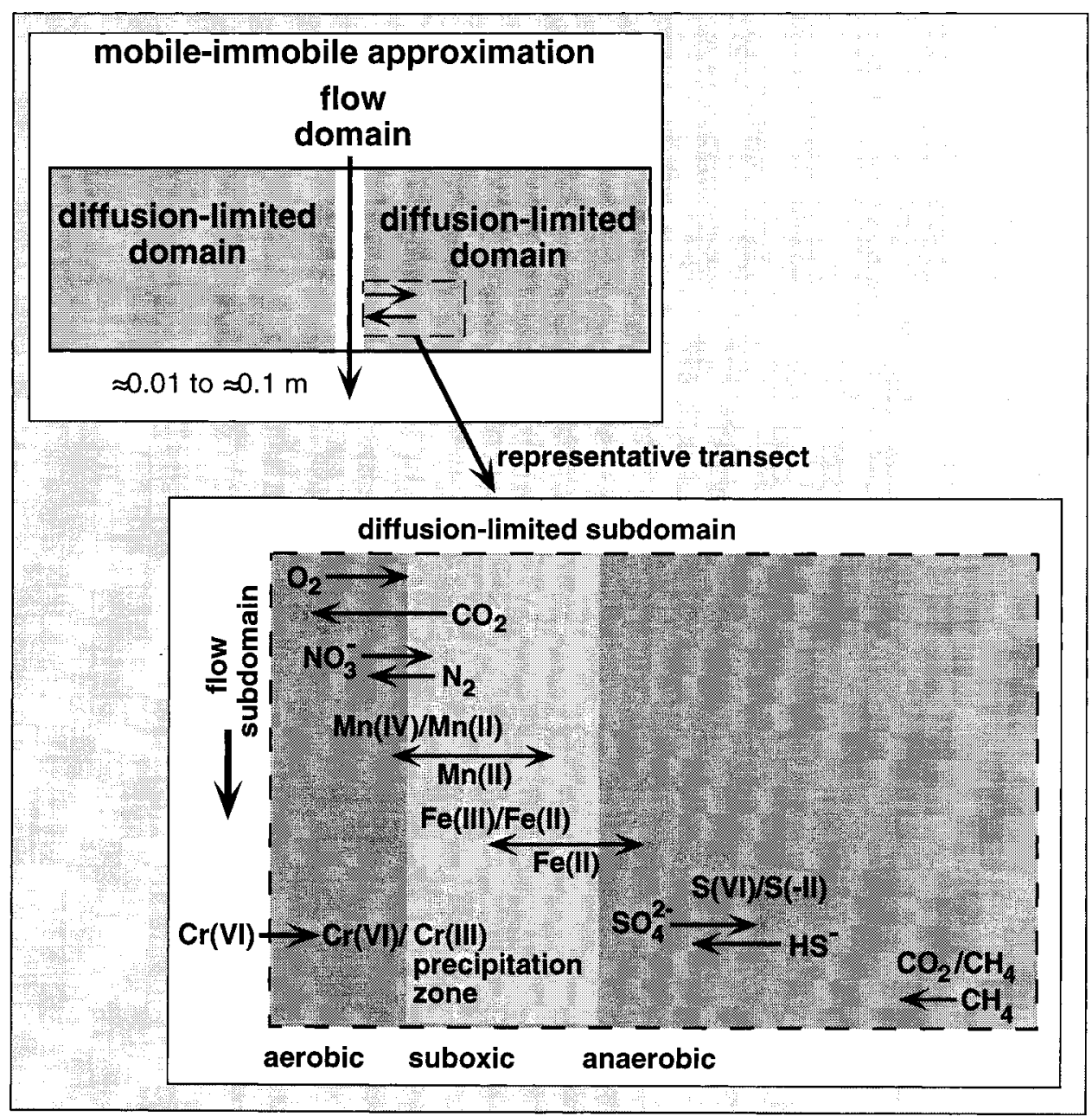

Fig. 1. Conceptual model of flow and transport in structured subsurface environments. Most of the flow occurs within the advective domain, which is often a small fraction of the system volume. The remaining larger fraction of the subsurface exchanges chemical species primarily through diffusion. Microbial activity can cause large gradients in redox potentials within these diffusion-limited domains, spatial stratification of redox processes, and localized precipitation of redox-sensitive contaminants.

also obscure contaminant deposition patterns that develop within more homogeneous matrices. Our previous work on Cr contamination was done using such homogeneous soils, in short columns designed to represent transects into soil aggregates (Tokunaga et al., 2001). In the present study, additional information from one homogeneous soil column is presented, along with results of experiments done directly on intact, field-collected soil aggregates. These experiments on natural aggregates were conducted to determine how applicable homogeneous model system results are for heterogeneous natural media. We also introduce an approach based on the Thiele modulus (Thiele, 1939) for estimating when intra-aggregate reactions are diffusion-limited.

\section{MATERIALS AND METHODS Synthetic Soil Aggregate}

Many details of the synthetic soil systems were presented in a previous study (Tokunaga et al., 2001). That study relied heavily on one-dimensional profiling of $\mathrm{Cr}(\mathrm{VI})$ and $\mathrm{Cr}(\mathrm{III})$ distributions using micro-X-ray absorption near edge structure (micro-XANES) spectroscopy (Bertsch and Hunter, 2001).
Since only one of these synthetic soil aggregates received further attention through two-dimensional micro-XANES mapping of $\mathrm{Cr}$, and deoxyribonucleic acid (DNA) fingerprinting, only its characteristics will be described here. Experiments were conducted on a small soil column designed to represent a transect into a large soil aggregate. Altamont clay (fine, smectitic, thermic Aridic Haploxerert; calcareous, 55\% clay, 23\% silt, $22 \%$ sand, C horizon, Altamont Pass, Alameda County, CA) soil was crushed, homogenized, and packed into a 30-mmlong column. Before introducing $\mathrm{Cr}(\mathrm{VI})$, the column was permeated with a solution containing $80 \mathrm{mg} \mathrm{L}^{-1}$ organic carbon (as tryptic soy broth, simulating decomposing soil organic matter), such that the soil became effectively saturated $(97 \%$ saturation). The outflow end of each column was sealed for the remainder of the experiment, such that it represented the center of a radially symmetric soil aggregate. A pin-hole vent at the opposite end of the column kept this boundary equilibrated with atmospheric air, thus representing the external surface of the aggregate. The carbon amendment was added to stimulate microbial respiration and accelerate the development of reducing conditions. The column was incubated at room temperature for $14 \mathrm{~d}$, after which a $260 \mathrm{mg} \mathrm{L}^{-1} \mathrm{Cr}(\mathrm{VI})$ solution of $\mathrm{K}_{2} \mathrm{CrO}_{4}$ was introduced to the exterior surface of the hydrostatic column, and allowed to diffuse inwards. Redox potentials were measured daily at 2 - to 5 -mm depth increments 
with Pt electrodes embedded through the column wall into the soil. Maps of $\mathrm{Cr}(\mathrm{VI})$ and $\mathrm{Cr}(\mathrm{III})$ distributions were obtained on the wet soil, as diffusion and reduction were proceeding using micro-XANES spectroscopy, as described later.

Bacterial communities in the synthetic aggregate were characterized with terminal restriction fragment length polymorphism (TRFLP) analysis of DNA extracted from the six sediment sections sampled from along the column (Liu et al., 1997, 1998). The DNA was extracted from samples with a soil DNA extraction kit (BIO 101, Carlsbad, CA). The conserved bacterial primers $27 \mathrm{~F}$ and $1492 \mathrm{R}$ were then used in a polymerase chain reaction (PCR) to generate fingerprints of the bacterial community (Liu et al., 1997). These primers target the 16S ribosomal gene of all bacteria. The $27 \mathrm{~F}$ primer was labeled with the fluorescent moiety 6-FAM. Conditions for the PCR reaction were as follows: the sediment DNA was melted for $30 \mathrm{~s}$ at $92^{\circ} \mathrm{C}$, annealing occurred at $53^{\circ} \mathrm{C}$ for $30 \mathrm{~s}$, and the PCR product was extended at $72^{\circ} \mathrm{C}$ for one minute. This cycle was repeated 26 times. The PCR products were digested with the endonuclease Msp I and analyzed on an ABI Prism 377 automatic DNA sequencer (Applied Biosystems, Foster City, CA). Principal component analysis was performed on the results with the JMP software package (SAS Institute, 1999) to relate changes in the community to total $\mathrm{Cr}$ concentration and redox potential of the sediment.

\section{Natural Soil Aggregates}

These experiments were designed to test for Cr redox zonation during contamination of natural, intact soil aggregates having different levels of microbial activity. Intact Altamont clay aggregates were obtained from the same location and depth from which soils were collected for the synthetic aggregate experiments. Large (90- to 150-mm dimensions), blocky aggregates with approximate spherical shape were selected to support transport with simple radial symmetry. Major to minor axis ratios of aggregates ranged from 1.05 to 1.3. The native Cr concentration in these aggregates ranged from 87 to $127 \mathrm{mg}$ $\mathrm{kg}^{-1}$, with $\geq 94 \%$ of this as $\mathrm{Cr}$ (III). To prevent breaking during wetting, aggregates were wrapped in cheesecloth, and supported in coarse sand in individual containers. To avoid damage to the aggregates, Pt redox electrodes were not inserted. Altamont soil solutions or tryptic soy broth was used to wet the soil aggregates (with solutions containing 0,80 , or $800 \mathrm{mg}$ $\mathrm{L}^{-1}$ organic carbon). Following $17 \mathrm{~d}$ of incubation, these aggregates were immersed in individual containers of $\mathrm{Cr}(\mathrm{VI})$ solutions $\left(1000 \mathrm{mg} \mathrm{L}^{-1}\right.$ initial $\mathrm{Cr}$, from $\left.19.2 \mathrm{mM} \mathrm{K} \mathrm{CrO}_{4}\right)$ for $3 \mathrm{~d}$, simulating the exposure of soils near a spill source during an episodic contamination event. The $\mathrm{Cr}$ solutions also contained $320 \mathrm{mg} \mathrm{L}^{-1} \mathrm{Br}^{-}$(from $4.0 \mathrm{mM} \mathrm{KBr}$ ) as a conservative tracer. This tracer was added to check for the possible artifact of solute displacement during the preservation procedure described next. After removal from $\mathrm{Cr}(\mathrm{VI})$ solution, one set of aggregates was immediately frozen $\left(-70^{\circ} \mathrm{C}\right)$, freeze-dried, and fixed with a low viscosity resin (LR White resin; London Resin Co. Ltd., Berkshire, UK). Another set of aggregates was incubated for an additional $28 \mathrm{~d}$ (room temperature) after removal from $\mathrm{Cr}(\mathrm{VI})$ solutions, then frozen, freeze-dried, and resin-fixed. The resin-fixed aggregates were cut to obtain 5 -mm-thick slab cross-sections. This provided two sets of preserved aggregates, one set fixed immediately after $3 \mathrm{~d}$ of $\mathrm{Cr}$ exposure, and the second set fixed at $31 \mathrm{~d}$ after the initial $\mathrm{Cr}$ exposure (but only immersed in the $\mathrm{Cr}$ solution for $3 \mathrm{~d}$ ). One surface of each slab was polished for synchrotron X-ray microprobe mapping of $\mathrm{Cr}$ and $\mathrm{Br}$ distributions. An additional set of aggregates was prepared in the same manner, without freezing and fixing with epoxy. This last set of aggregates was triplicate cored to characterize depth profiles of microbial communities by phospholipid fatty acid (PLFA) analyses (Tunlid et al., 1989), enzyme analyses (Casida, 1977), and the population density and activity of total microorganisms as measured by direct fluorochrome staining (Lloyd and Hayes, 1995), and for additional Cr XANES analyses. Thus, there were two sets of aggregates (one resin-fixed and the other not) for each combination of initial organic carbon $(+0,+80$ and $+800 \mathrm{mg} \mathrm{L}^{-1}$ ) and termination date (Day 3 or Day 31 ).

Besides solute displacement, another important class of potential artifacts associated with aggregate preservation is that of chemical alteration. In this study, we are particularly concerned with possible reduction of $\mathrm{Cr}(\mathrm{VI})$ during resin-fixing of the aggregates. To test for this artifact, homogenized Altamont soil samples (102 $\mathrm{mg} \mathrm{kg}^{-1} \mathrm{Cr}$, native soil concentration) were spiked with $\mathrm{K}_{2} \mathrm{CrO}_{4}$ solutions to obtain final soil concentrations of 196,395 , and $583 \mathrm{mg} \mathrm{Cr}(\mathrm{VI}) \mathrm{kg}^{-1}$. Soils were air-dried overnight, preserved with the same resin applied to the natural aggregates, and analyzed for total $\mathrm{Cr}$ and $\mathrm{Cr}(\mathrm{VI})$ concentrations as described below.

\section{X-Ray Microprobe and Micro-X-Ray Absorption Near-Edge Structure Mapping}

$\mathrm{X}$-ray microprobe and micro-XANES maps of synthetic soil aggregates were obtained on the GeoSoilEnviroCARS Beamline 13ID-C at the Advanced Photon Source (Argonne National Laboratory, Argonne, IL). Procedures used have been described previously (Tokunaga et al., 2001). The X-ray microprobe map of $\mathrm{Cr}$ in the synthetic aggregate presented here was collected over a 10 - by 3.6-mm area, in 0.1-mm steps. Elemental mapping and Cr micro-XANES of the natural soil aggregates were performed at Beamline X26A of the National Synchrotron Light Source (Brookhaven National Laboratory, Upton, NY). All measurements done at the National Synchrotron Light Source utilized a large $300-$ by $300-\mu \mathrm{m}$ beam that projects onto samples as $300 \mu \mathrm{m}$ in the vertical by $420 \mu \mathrm{m}$ in the horizontal due to $45^{\circ}$ orientation of the sample surface relative to the incident beam. Although much finer spot sizes are routinely used, this large spot size was selected to average over many mineral grains and pores. Relative concentrations of $\mathrm{Cr}(\mathrm{VI})$ were determined from the background-subtracted, pre-edge peak fluorescence, normalized to the Cr K-edge step height (Fig. 2). Four types of measurements were obtained on natural aggregate materials. The first involved scanning pre-

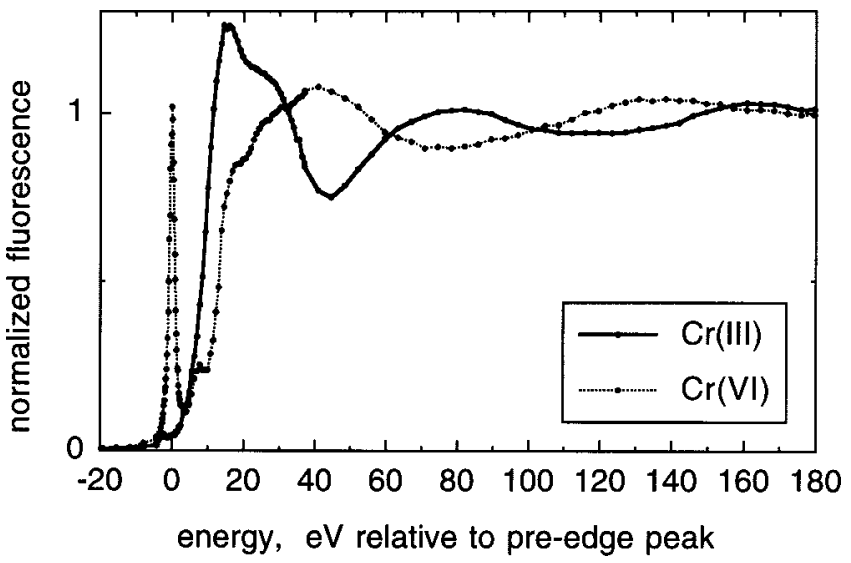

Fig. 2. Chromium K-edge $\mathrm{X}$-ray absorption near-edge structure (XANES) of $\mathrm{Cr}$ (III) and $\mathrm{Cr}(\mathrm{VI})$. The X-ray fluorescence intensity at the pre-edge peak energy (at $0 \mathrm{eV}$ on the relative energy scale) is normalized to the edge step height (average fluorescence in the relative energy range of +150 to $+180 \mathrm{eV}$ ). 
served aggregates with the monochromator energy set at 13.75 $\mathrm{keV}$, about $270 \mathrm{eV}$ above the $\mathrm{Br} \mathrm{K}$-edge, to measure spatial distributions of $\mathrm{Br}^{-}$. The second type of measurements consisted of micro-XANES scans of Altamont soils spiked with three different amounts of $\mathrm{Cr}(\mathrm{VI})$ solutions, dried overnight, and resin-fixed. These samples served as calibration standards for total $\mathrm{Cr}$ concentrations in the preserved aggregates, and as a check for a possible $\mathrm{Cr}(\mathrm{VI})$ reduction artifact incurred during the preservation process. The third series of measurements involved two-dimensional mapping of total $\mathrm{Cr}$ distributions in the resin-fixed aggregate slices. For these scans, the monochromator energy was set at about $130 \mathrm{eV}$ above the $\mathrm{Cr}(\mathrm{VI})$ pre-edge peak energy (take as $5993 \mathrm{eV}$ ), and $x-y$ translations of the sample were done on 0.5 - or $1-\mathrm{mm}$ increments. Scan times varied from 10 to 20 s per sample spot, with net $\mathrm{Cr} \mathrm{K}_{\alpha}$ fluorescence counts normalized to ion chamber counts. Even with the coarse mapping grid and short count times, experimental time constraints allowed for mapping only about 30by $30-\mathrm{mm}$ areas within each aggregate slice $(10-20 \%$ of the total slice area of each aggregate). The fourth and final type of measurements was done on triplicate core samples collected from each Day 3 and Day 31 aggregate, immediately sectioned and refrigerated (no freeze-drying or resin treatment) before their micro-XANES measurements $41 \mathrm{~d}$ later. Each core was sectioned into five segments, 8 to $12 \mathrm{~mm}$ in length. The analyses of $\mathrm{Cr}(\mathrm{VI})$ reduction in natural aggregates were based on these $\mathrm{Cr}$ micro-XANES measurements of core plugs.

\section{RESULTS AND DISCUSSION}

\section{Synthetic Soil Aggregates}

Redox measurements showed that oxic conditions were dominant only within the outmost approximately $1 \mathrm{~mm}$ of these soils (pre-incubated with $80 \mathrm{mg} \mathrm{L}^{-1}$ organic carbon solution), and that reducing conditions were preserved at depths $\geq 5 \mathrm{~mm}$, before, during, and after exposure to $\mathrm{Cr}(\mathrm{VI})$ solutions (Fig. 3). Transient increases in redox potentials at the 1- and 3-mm depths were recorded in response to transport of $\mathrm{Cr}(\mathrm{VI})$. Under these reducing conditions (redox potentials $<-100$ $\mathrm{mV}$ ), diffusion from the finite $260 \mathrm{mg} \mathrm{L}^{-1} \mathrm{Cr}(\mathrm{VI})$ reser-

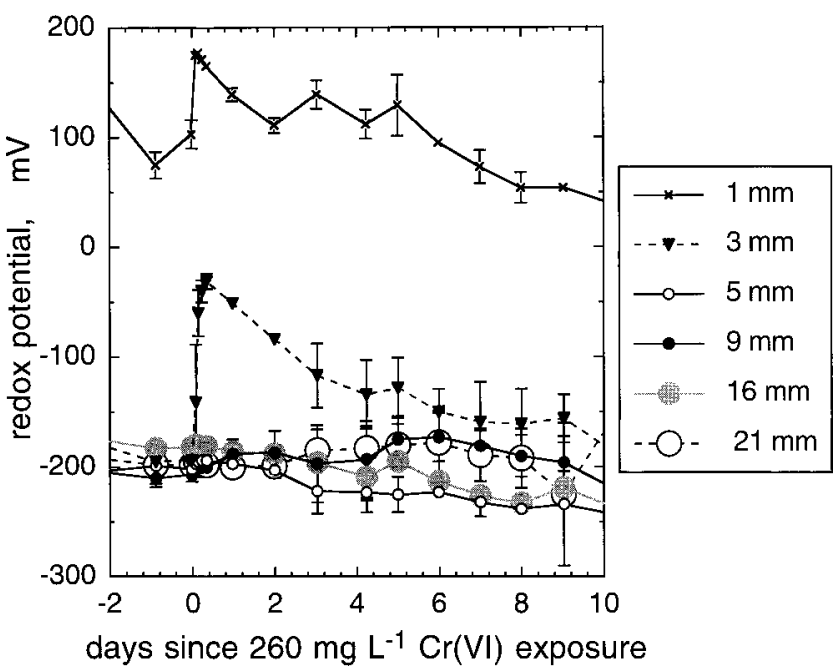

Fig. 3. Time trends for redox potentials measured at various depths in a synthetic soil aggregate exposed to $260 \mathrm{mg} \mathrm{L}^{-1} \mathrm{Cr}$ (VI) on Day 0 . Data points are averages of readings from duplicate electrodes, and range bars indicate their individual values. voir was limited to distances of a few millimeters. MicroXANES analyses confirmed that abrupt termination of $\mathrm{Cr}$ transport was a result of reduction to insoluble Cr(III) (Tokunaga et al., 2001). The Cr(III) precipitation zone was sharply defined, with only about $0.2 \mathrm{~mm}$ separating measured highly contaminated and uncontaminated regions within the soil (Fig. 4b). The actual boundary between these regions may be even sharper, since a broad beam size of $250 \mu \mathrm{m}$ was used on this sample. Good agreement was found between this $\mathrm{Cr}$ map and the $\mathrm{Cr}$ distribution inferred from a single line scan of this same soil (Fig. 4a in Tokunaga et al., 2001). Principal component analysis of terminal restriction fragment length polymorphism (TRFLP) patterns distinguished the aggregate regions exposed to $\mathrm{Cr}(\mathrm{VI})$ from unexposed regions (Fig. 4c). The three clustered "fingerprints" in the lower right of Fig. 4c represent the non-Cr-impacted bacterial community present in the "interior" 9- to 25-mm sections of the column. The outermost section of the column $(0-2 \mathrm{~mm})$, exposed to the

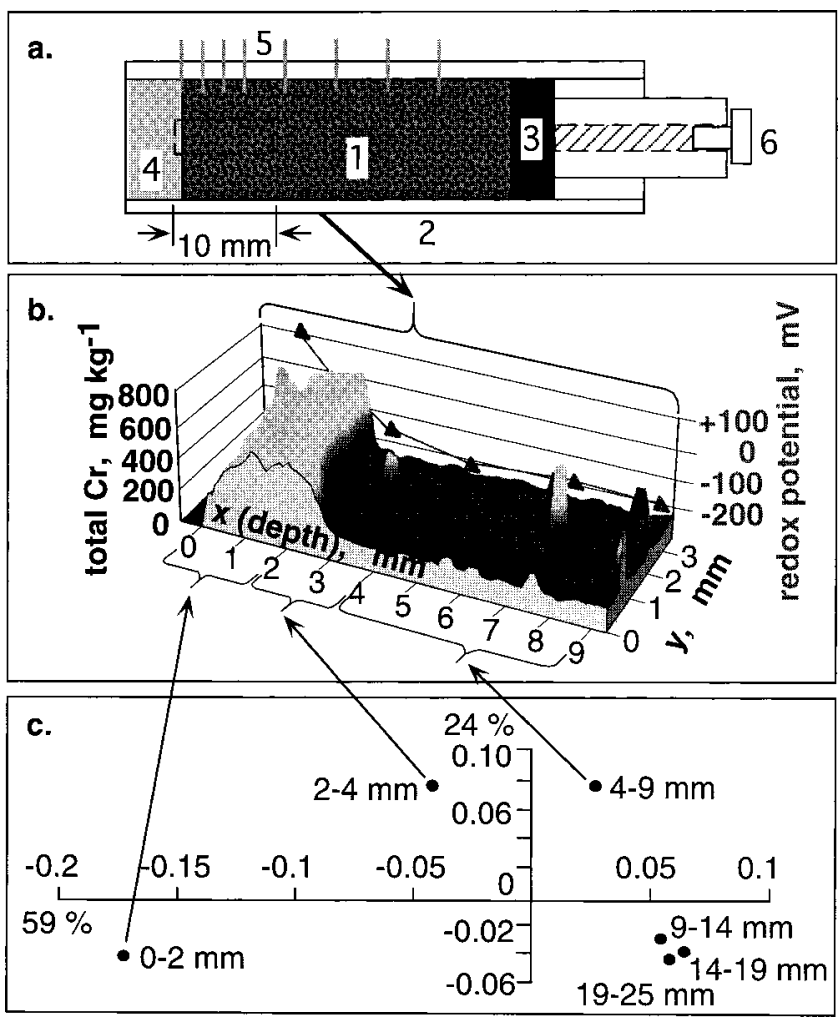

Fig. 4. (a) Synthetic soil aggregate column design. (1) Homogeneous soil pack, (2) plastic column, (3) piston for soil extrusion, (4) boundary reservoir for $\mathrm{Cr}(\mathrm{VI})$ solution, (5) Pt redox electrodes, and (6) plug. (b) X-ray microprobe map (3.0 by $9.5 \mathrm{~mm})$ of total $\mathrm{Cr}$ in a synthetic soil aggregate, pre-incubated with $80 \mathrm{mg} \mathrm{L}^{-1}$ organic carbon solution, and exposed to a pool of $260 \mathrm{mg} \mathrm{L}^{-1} \mathrm{Cr}(\mathrm{VI})$ for $2.5 \mathrm{~d}$. Greater than $95 \%$ of the contaminant was reduced to $\mathrm{Cr}$ (III) within $2 \mathrm{~mm}$ of the exposure surface. The native soil $\mathrm{Cr}$ is at least $95 \%$ in the $\mathrm{Cr}$ (III) oxidation state, with an average concentration of $150 \mathrm{mg} \mathrm{kg}^{-1}$, but heterogeneously distributed (note $\mathrm{Cr}$ map at depths greater than about $2 \mathrm{~mm}$ ). A characteristic redox potential profile is plotted over the $\mathrm{Cr}$ map. (c) Principal component plot of bacterial terminal restriction fragment length polymorphism (TRFLP) patterns from the synthetic soil aggregate showing changes in bacterial community composition occurring in domains defined by $[\mathrm{Cr}]$ and redox potential. 
highest concentrations of total Cr, revealed TRFLP patterns of bacterial DNA most distant in principal component space from the non-exposed interior communities. The 2- to 4- and 4- to 9-mm sections were then intermediate between the most external section and the interior domain. The differences in TRFLP patterns in sections along the column indicated that the bacterial communities exposed to high concentrations of $\mathrm{Cr}$ were substantially different than the interior communities experiencing indigenous concentrations of $\mathrm{Cr}$ and lower redox potentials. In previous experiments, ribosomal intergenic spacer analysis also showed that unique intergenic sequences were present in the region exposed to $\mathrm{Cr}(\mathrm{VI})$, suggesting selection of $\mathrm{Cr}(\mathrm{VI})$-resistant organisms (Tokunaga et al., 2001). Control tests in sterile soils with the same levels of organic carbon and $\mathrm{Cr}(\mathrm{VI})$ showed negligible $(<5 \%) \mathrm{Cr}$ reduction by Day 14 , indicating that microbial activity was essential for obtaining significant reduction within the experimental time frame. While $\mathrm{Cr}(\mathrm{VI})$ reduction appeared to be primarily dependent on microbial activity, we could not distinguish whether the reduction resulted from $\mathrm{Cr}(\mathrm{VI})$-reducing bacteria (tolerant to high $\mathrm{Cr}$ concentrations) in the outermost sediment or from bacteria residing in interior zones, largely protected from $\mathrm{Cr}$ exposure, that were responsible for generation of reactive reductants such as $\mathrm{Fe}(\mathrm{II})$.

\section{Bromide Distribution in Natural Soil Aggregates}

Bromide concentration profiles obtained on the resinfixed aggregates with the X-ray microprobe exhibited diffusion profiles, indicating that the aggregate preservation procedure did not cause redistribution of solutes. Example elemental distributions from an aggregate preincubated with $800 \mathrm{mg} \mathrm{L}^{-1}$ organic carbon, and preserved after $3 \mathrm{~d}$ of $\mathrm{CrO}_{4}^{2-}$ and $\mathrm{Br}^{-}$diffusion, are shown in Fig. 5. To show several profiles on a common scale, net X-ray fluorescence counts were normalized to their

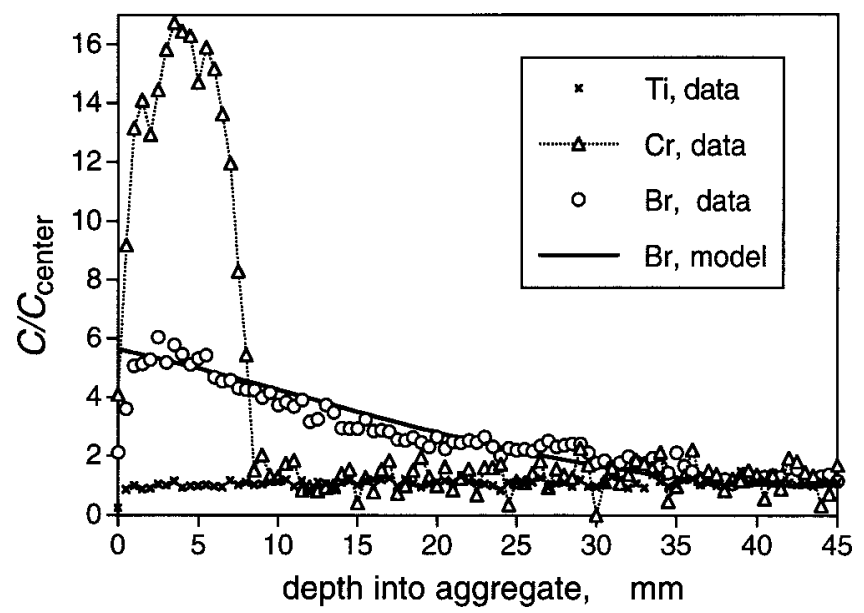

Fig. 5. X-ray microprobe profiles of $\mathrm{Ti}, \mathrm{Cr}$, and $\mathrm{Br}$, obtained on an aggregate incubated with $800 \mathrm{mg} \mathrm{L}^{-1}$ organic carbon, then placed in diffusive contact with a reservoir containing $1000 \mathrm{mg} \mathrm{L}^{-1}(19.2$ $\mathrm{mM}) \mathrm{Cr}(\mathrm{VI})$ and $320 \mathrm{mg} \mathrm{L}^{-1}(4.0 \mathrm{mM}) \mathrm{Br}^{-}$for $3 \mathrm{~d}$. After removal from the reservoir, the aggregate was immediately frozen, freezedried, and resin-fixed. average values within the deepest 7 -mm interval (i.e., the 38- to 45-mm interval in this case) (Fig. 5). The Ti profile is included to provide an indication of matrix heterogeneity. Note that the $\mathrm{Br}^{-}$distribution is in good agreement with the profile predicted from a finite-difference diffusion calculation for this system. For this calculation, an effective $\mathrm{Br}^{-}$diffusivity of $3.0 \times 10^{-4}$ $\mathrm{mm}^{2} \mathrm{~s}^{-1}$ was used; being the product of its aqueous phase diffusivity of $1.8 \times 10^{-3} \mathrm{~mm}^{2} \mathrm{~s}^{-1}$ (Robinson and Stokes, 1959), measured porosity of 0.38 , and assumed tortuosity factor of 0.44 . The reasonable diffusion profiles obtained for $\mathrm{Br}^{-}$in these aggregates provided confidence that solutes were not displaced by the resin preservation procedure. Therefore, maps of spatial distributions of total $\mathrm{Cr}$ in resin-preserved aggregates are reliable. In strong contrast to the diffuse $\mathrm{Br}^{-}$profile, the advancing $\mathrm{Cr}$ front terminates very sharply at about an 8-mm depth. Distributions of total $\mathrm{Cr}$ and $\mathrm{Cr}(\mathrm{VI})$ in aggregates are discussed in a following section.

\section{Chromate Reduction in Resin-Fixed Soils}

Chromium XANES measurements on soil samples that were resin-fixed $1 \mathrm{~d}$ after spiking with up to $583 \mathrm{mg}$ $\mathrm{kg}^{-1} \mathrm{Cr}(\mathrm{VI})$ showed very significant reduction to $\mathrm{Cr}(\mathrm{III})$. On average, $85 \%$ of the spiked $\mathrm{Cr}(\mathrm{VI})$ was reduced by the epoxy resin treatment (Fig. 6). The combined evidence from $\mathrm{Br}$ and $\mathrm{Cr}$ maps of soil aggregate sections, and from $\mathrm{Cr}(\mathrm{VI})$-spiked, resin-fix test samples shows that the resin-fixing procedure did not transport either $\mathrm{Br}$ or $\mathrm{Cr}$, but did cause substantial $\mathrm{Cr}(\mathrm{VI})$ reduction. Thus, samples prepared with this resin could be used reliably for mapping elemental distributions, but not for $\mathrm{Cr}$ oxidation state determination. The possibility of redox artifact needs to be evaluated on a case by case basis. Tests on Se in soils and As-spiked iron oxides did not exhibit resin-associated redox artifacts, while some As-spiked soils did (personal communications from D. Strawn, University of Idaho; H.E. Doner, University of California, Berkeley; and M. Zavarin, Lawrence Livermore National Laboratory).

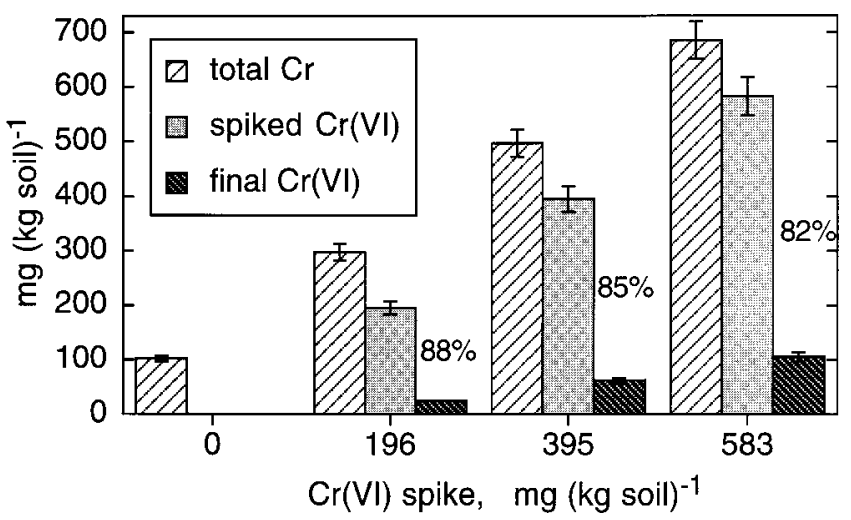

Fig. 6. Reduction of $\mathrm{Cr}(\mathrm{VI})$ to $\mathrm{Cr}(\mathrm{III})$ after resin-preserving $\mathrm{CrO}_{4}^{2-}-$ spiked Altamont soil. Percentages shown on bars indicate the relative amounts of the initial spikes that were reduced on resin-treating. Error bars indicate standard deviations ( 36 measurement spots per sample). 


\section{Chromium and Microbial Activity Distributions in Natural Soil Aggregates}

$\mathrm{X}$-ray microprobe maps of $\mathrm{Cr}$ distributions in resinfixed aggregates were collected in only 10 to $20 \%$ of each section because of their relatively large total sample area. Measured $\mathrm{Cr}$ distributions in natural aggregates (Fig. 7c) are very similar to those obtained in the synthetic aggregates used in our earlier study. Some variability in $\mathrm{Cr}$ distributions is expected from heterogeneity (local mineralogy, porosity, diffusivity, and redox) within and among these natural aggregates. Nevertheless, aggregates with higher available organic carbon reductively precipitated $\mathrm{Cr}$ (III) within shorter distances, and took up higher amounts of $\mathrm{Cr}$ through maintaining higher concentration gradients for the diffusing $\mathrm{Cr}(\mathrm{VI})$. Day 3 maps (Fig. 7c, left panels) exhibit patterns indicative of the initial stages of $\mathrm{Cr}$ diffusion, whereas the Day 31 maps (Fig. 7c, right panels) reflect longer-term $\mathrm{Cr}$ redistribution and precipitation within kinetically favorable (i.e., more reducing) zones. Sharp termination of the $\mathrm{Cr}$ front is evident in the later stages of the +80 and $+800 \mathrm{mg} \mathrm{L}^{-1}$ organic carbon (OC) aggregates. Chromium diffused into $99( \pm 1), 80( \pm 7)$, and $50( \pm 5) \%$ of the available soil volume in the aggregates with 0 , +80 , and the $+800 \mathrm{mg} \mathrm{L}^{-1}$ organic carbon, respectively. This amounted to increases in average $\mathrm{Cr}$ concentrations of $212( \pm 20), 406( \pm 60)$, and $1350( \pm 140) \mathrm{mg} \mathrm{kg}^{-1}$ $\mathrm{Cr}$ in the contaminated regions of the $+0,+80$, and the $+800 \mathrm{mg} \mathrm{L}^{-1}$ organic carbon aggregates, respectively. These estimates were based on approximating aggregates as spheres, and measuring $\mathrm{Cr}$ profiles along five radial transects within mapped sections. Thus, total $\mathrm{Cr}$ concentrations were weighted by the cube of their associated radial distances from the centers of aggregates. It is worth noting that additional scans of Day 31 aggregates over larger areas (up to 50\% coverage) yielded results in agreement with the above calculations.

The spatial distribution of microbial activity in these aggregates, rather than total microbial biomass, appeared to drive the creation of redox gradients and resulting $\mathrm{Cr}$ zonation. Dehydrogenase activity within the
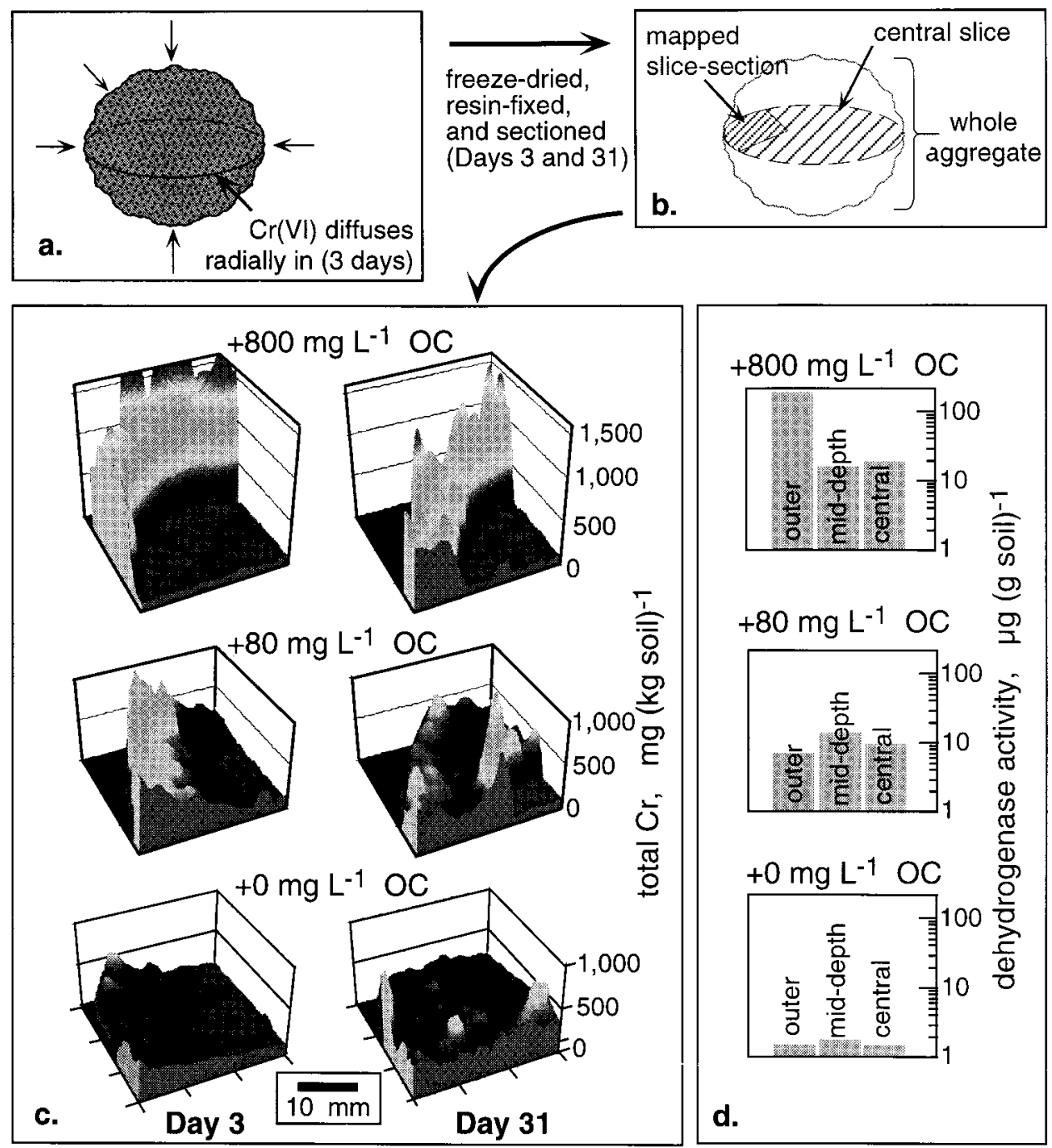

Fig. 7. (a) Diffusion of Cr(VI) into natural soil aggregates. (b) Sectioning of aggregates for X-ray mapping. (c) Maps of total Cr distributions from aggregate sections (different levels of organic carbon [OC], Days 3 and 31). (d) Dehydrogenase activities (7-d incubations) at different levels of $\mathrm{OC}$ addition and different depths (nominally 0 - to 10-, 20- to 30-, and 40- to 50-mm depths), averaged over $31 \mathrm{~d}$. 
aggregates was highest in the outermost $(0-20 \mathrm{~mm})$ regions of aggregates presaturated with $800 \mathrm{mg} \mathrm{L}^{-1}$ organic carbon (Fig. 7d). In contrast, deeper parts of these same aggregates (the 20 - to 60 -mm depths) had average dehydrogenase concentrations that were no higher than $17 \%$ of that of outer regions. Total microbial biomass was not significantly affected by exposure to $\mathrm{Cr}$ or by differing concentrations of organic carbon. The phospholipid fatty acid (PLFA) biomass ranged from 0.179 to $75.3 \mu \mathrm{g}$ PLFA g ${ }^{-1}$ soil with a mean of $5.56 \mu \mathrm{g} \mathrm{g}^{-1}$ soil $(N=108)$, while the direct counts by epifluorescent microscopy ranged from $2.86 \times 10^{8}$ to $3.23 \times 10^{9}$ cells g $^{-1}$, with a mean of $1.26 \times 10^{9}$ cells g $^{-1}(N=108)$. Factorial analysis of variance revealed that only dehydrogenase showed a significant pattern by factors used in the experimental design.

Micro-XANES analyses of refrigerated core plug sections yielded similar total $\mathrm{Cr}$ depth distributions as those obtained in the two-dimensional maps. The depth distributions of the $\mathrm{Cr}(\mathrm{VI})$ to total $\mathrm{Cr}$ ratio from the Day 3 and 31 cores are shown in Fig. 8. It should be noted that these measurements were obtained $41 \mathrm{~d}$ after collection of the core plugs. Although they were kept refrigerated before X-ray analyses, it is likely that some changes in $\mathrm{Cr}$ oxidation state still occurred during storage. The transported $\mathrm{Cr}$ was largely reduced to $\mathrm{Cr}(\mathrm{III})$, with only $30( \pm 6), 12( \pm 3)$, and $3( \pm 1) \%$ remaining as $\mathrm{Cr}(\mathrm{VI})$ by Day 31 in the $+0,+80$, and $+800 \mathrm{mg} \mathrm{L}^{-1}$
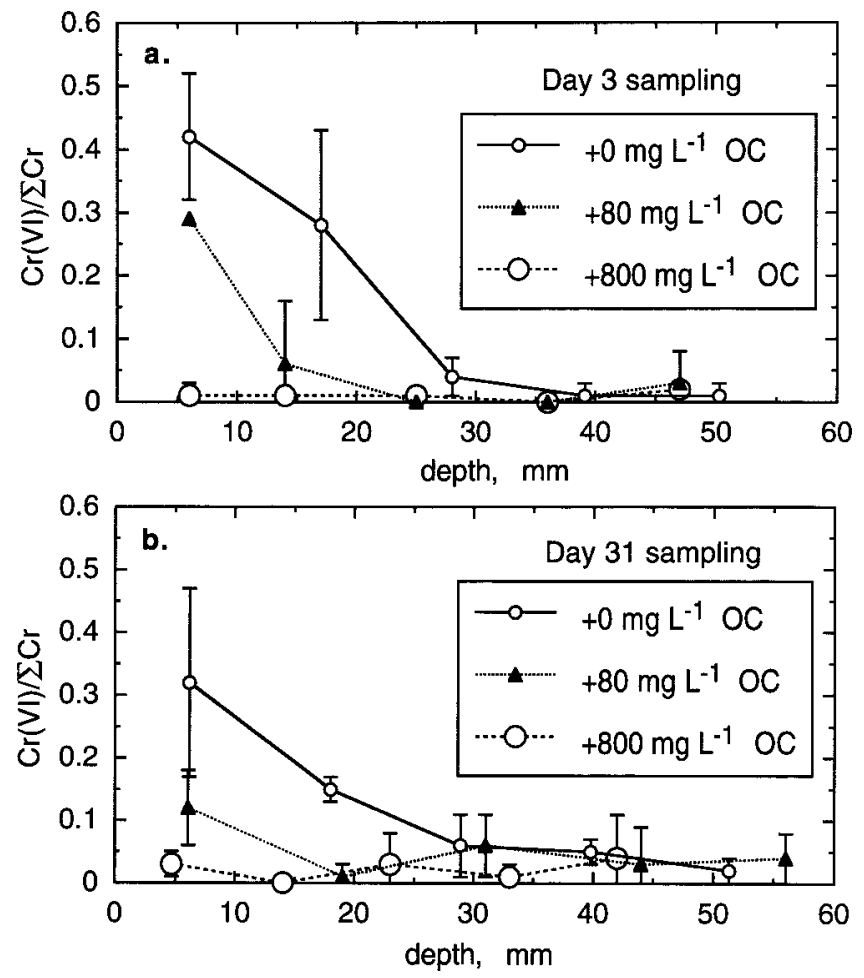

Fig. 8. Depth profiles of total $\mathrm{Cr}$ and $\mathrm{Cr}(\mathrm{VI})$ concentrations from Days $3(a)$ and $31(b)$ core plug sampling of soil aggregates preincubated with different levels of organic carbon (OC). Plots are from triplicate cores of the soils, with variability indicated by range bars. The micro-X-ray absorption near-edge structure (XANES) measurements were made on samples refrigerated for $41 \mathrm{~d}$ after coring, without freeze-drying or resin-fixing. organic carbon systems, respectively. These values were obtained based on the spherical symmetry approximation described previously. Although very little of the original $\mathrm{Cr}$ contaminant that diffused into each aggregate remains as $\mathrm{Cr}(\mathrm{VI})$ by Day 31 , it is important to recognize that this unreduced fraction remains along the exterior region of aggregates. In the larger context of transport through soil profiles, fast flow paths occur between individual soil aggregates. Therefore, the remaining $\mathrm{Cr}(\mathrm{VI})$ resides in the immediate proximity of preferential transport pathways.

\section{Similar Processes and Implications}

Processes and environments where highly localized redox gradients have been extensively studied include denitrification in aggregates (Currie, 1961; Smith, 1977; Zausig et al., 1993) and redox zonation at water-sediment boundaries (Berner, 1980; Santschi et al., 1990). Within soil aggregates, the coupling of microbial respiration, diffusion limited oxygen supply, and redox zonation also influences the fate of other redox-sensitive elements including chlorinated organics and trace element contaminants (Enzien et al., 1994; Tokunaga et al., 1994; Tokunaga et al., 2001). Given sufficiently large diffusion distances and respiration rates, the full spectrum of redox conditions relevant to contaminant transformations in some field sites can be contained within individual soil aggregates.

Similar diffusion-reaction problems were analyzed to optimize the efficiency of porous pellet catalysis within packed bed reactors (Thiele, 1939; Weisz, 1973). The Thiele modulus, $\Phi$, is a dimensionless parameter useful in deducing when the efficiency of a catalytic pellet is diffusion-limited or reaction rate-limited. In environmental systems, $\Phi$ has been used in studies of denitrification in aggregated soil (Myrold and Tiedje, 1985) and toluene degradation in biofilms (Holden et al., 1997). For systems that can be approximated with first-order reaction rates and constant diffusivities, the Thiele modulus is defined by:

$$
\Phi=R \sqrt{\frac{k}{D_{\mathrm{e}}}}
$$

where $R$ is the radius of the pellet (aggregate), $k$ is the effective first-order rate constant, and $D_{\mathrm{e}}$ is the effective diffusivity of reactants in the pellet (aggregate). Reactions during flow through columns consisting of pellets (aggregates) are limited by kinetics or diffusion, depending on whether $\Phi$ is small $(<0.3)$ or large $(>3)$, respectively. Effective diffusivities of most nonsorbing aqueous-phase solutes in saturated soils are in the range of about $2 \times 10^{-4}$ to $5 \times 10^{-4} \mathrm{~mm}^{2} \mathrm{~s}^{-1}$. Using an effective diffusivity of $4 \times 10^{-4} \mathrm{~mm}^{2} \mathrm{~s}^{-1}$ as a reference, the dependence of critical values of $\Phi$ on aggregate size and effective first-order reaction rates can be plotted, as shown in Fig. 9. This Thiele analysis indicates that transformations in aggregates involving $k$ values greater than about $10^{-4} \mathrm{~s}^{-1}$ and diffusion distances greater than about $5 \mathrm{~mm}$ are either strongly influenced or determined by diffusion rather than by reaction rates. Reaction rate con- 


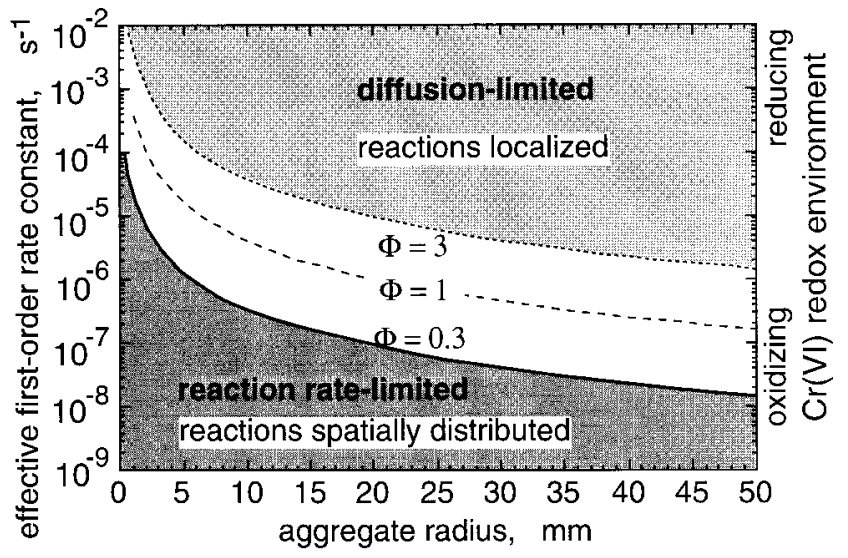

Fig. 9. Predicted dispersed or localized reduction of $\mathrm{Cr}(\mathrm{VI})$ within soil aggregates, depending on aggregate-size and effective first-order reduction rate constant. Approximate boundaries for reaction ratelimited $(\Phi=0.3)$ versus diffusion-limited $(\Phi=3)$ conditions are based on Thiele's (1939) analysis, using an effective diffusivity of $4 \times 10^{-4} \mathrm{~mm}^{2} \mathrm{~s}^{-1}$.

stants obtained for $\mathrm{Cr}(\mathrm{VI})$ reduction by ferrous iron (Sedlak and Chan, 1997), green rusts (Williams and Scherer, 2001), and sulfides (Pettine et al., 1994) are high enough in anoxic soils and sediments (e.g., $k>$ $10^{-4} \mathrm{~s}^{-1}$ ) such that transformation times for conversion to $\mathrm{Cr}(\mathrm{III})$ will be determined by diffusion. Thus, for $\mathrm{Cr}(\mathrm{VI})$, its diffusion into suboxic and anoxic aggregates can result in very localized $\mathrm{Cr}$ (III) precipitation fronts, beyond which $\mathrm{Cr}$ transport is prohibited. The domain of such diffusion-limited conditions is indicated in the upper portion of Fig. 9. When solution species undergo sorption-desorption, their diffusive transport is more retarded, and even more influential in controlling effective reaction rates (larger values of $\Phi$ ). Transport retardation by sorption-desorption will occur for $\mathrm{HCrO}_{4}^{-}$ (Zachara et al., 1989) and other oxyanions (Sposito, 1984) in acidic to neutral soils. Under more aerobic conditions where humic substances and microorganisms are largely responsible for direct $\mathrm{Cr}(\mathrm{VI})$ reduction (Fendorf et al., 2000), characteristic reaction rates are slow enough such that diffusion is not a significant limitation. Under these conditions, $\mathrm{Cr}(\mathrm{VI})$ can become well-dispersed in soil before precipitating. The domain for such reaction rate-limited $\mathrm{Cr}(\mathrm{VI})$ reduction in oxidizing soils is shown in the lower portion of Fig. 9. Note that the conditions tested in our soil aggregates (Fig. 7) illustrate both diffusion- and reaction rate-limited cases.

\section{CONCLUSIONS}

Chromium contamination within biologically active soil aggregates can be strongly diffusion-limited, resulting in reduction to insoluble $\mathrm{Cr}$ (III) within short distances. In large diffusion-limited domains, the $\mathrm{Cr}$ contamination can be restricted to outer regions in contact with preferential flow paths, leaving the deeper core region unaffected. Such aggregates contain microbial communities that have and have not been exposed to $\mathrm{Cr}(\mathrm{VI})$ residing within outer and core regions, respectively. These results show the importance of intra-aggregate spatial relations for redox sensitive contaminants as well as for the microbial communities responsible for redox gradients and reductants. By extension, similar stratification of redox potentials, metal contaminants, and microbial communities might occur within larger sediment blocks deeper in the subsurface. In soils and sediments comprised of aggregates or blocks that support internal redox gradients, bulk characterization of chemical and microbiological characteristics does not allow mechanistic understanding of biogeochemical processes.

\section{ACKNOWLEDGMENTS}

We thank Robert Giauque, Tracy Letain, Dominique Joyner, and Andrew Mei of LBNL, and GSECARS staff for assistance. Very helpful internal review comments of an earlier version of this manuscript by Harvey Doner (University of California, Berkeley, and LBNL), and of the final manuscript by two anonymous reviewers are gratefully acknowledged. Funding was provided through the U.S. Department of Energy, Natural and Accelerated Bioremediation Research Program, and Basic Energy Sciences, Geosciences Program, under Contract no. DE-AC03-76SF00098. Use of the Advanced Photon Source was supported by the U.S. Department of Energy, Basic Energy Sciences, Office of Science, under Contract no. W-31-109Eng-38. Research carried out (in part) at the National Synchrotron Light Source, Brookhaven National Laboratory, which is supported by the U.S. Dep. of Energy, Division of Materials Sciences and Division of Chemical Sciences.

\section{REFERENCES}

Berner, R.A. 1980. Early diagenesis. Princeton Univ. Press, Princeton, NJ.

Bertsch, P.M., and D.B. Hunter. 2001. Applications of synchrotronbased x-ray microprobes. Chem. Rev. 101:1809-1842.

Casida, L.E. 1977. Microbial metabolic activity in soil as measured by dehydrogenase determinations. Appl. Environ. Microbiol. 34: 630-636.

Chapelle, F.H. 1992. Ground-water microbiology and geochemistry. John Wiley \& Sons, New York.

Currie, J.A. 1961. Gaseous diffusion in the aeration of aggregated soils. Soil Sci. 92:40-45.

Drazkiewicz, M. 1994. Distribution of microorganisms in soil aggregates-Effect of aggregate size. Folia Microbiol. (Prague) 39:276-282.

Enzien, M.V., F. Picardal, T.C. Hazen, R.G. Arnold, and C.B. Fliermans. 1994. Reductive dechlorination of trichloroethylene and tetrachloroethylene under aerobic conditions in a sediment column. Appl. Environ. Microbiol. 60:2200-2204.

Fendorf, S., B.W. Wielinga, and C.M. Hansel. 2000. Chromium transformations in natural environments: The role of biological and abiological processes in chromium(VI) reduction. Int. Geol. Rev. 42: 691-701.

Holden, P.A., J.R. Hunt, and M.K. Firestone. 1997. Toluene diffusion and reduction in unsaturated Pseudomonas putida biofilms. Biotechnol. Bioeng. 56:656-670.

James, B.R. 1996. The challenge of remediating chromium-contaminated soil. Environ. Sci. Technol. 30:248A-251A.

Liu, W.T., T.L. Marsh, H. Cheng, and L.J. Forney. 1997. Characterization of microbial diversity by determining terminal restriction fragment length polymorphisms of genes encoding 16S RNA. Appl. Environ. Microbiol. 63:4516-4522.

Liu, W.T., T.L. Marsh, and L.J. Forney. 1998. Determination of the microbial diversity of anaerobic-aerobic activated sludge by a novel molecular biological technique. Water Sci. Technol. 37:417-422.

Lloyd, D., and A. Hayes. 1995. Vigour, vitality and viability of microorganisms. FEMS Microbiol. Lett. 133:1-7.

Losi, M.E., C. Amrhein, and W.T. Frankenberger, Jr. 1994. Bioremediation of chromate-contaminated groundwater by reduction and precipitation in surface soils. Environ. Toxicol. Chem. 13:1727-1735.

Losi, M.E., and W.T. Frankenberger, Jr. 1994. Chromium-resistant 
microorganisms isolated from evaporation ponds of a metal processing plant. Water Air Soil Pollut. 74:405-413.

Lovley, D.R. 1993. Dissimilatory metal reduction. Annu. Rev. Microbiol. 47:263-290.

Lovley, D.R., E.J.P. Phillips, and D.J. Lonergan. 1991. Enzymatic versus nonenzymatic mechanisms for $\mathrm{Fe}(\mathrm{III})$ reduction in aquatic sediments. Environ. Sci. Technol. 25:1062-1067.

Makdisi, R.S. 1992. Tannery wastes definition, risk assessment, and cleanup options, Berkeley, California. J. Hazard. Mater. 29:79-96.

Myrold, D.D., and J.M. Tiedje. 1985. Diffusional constraints on denitrification in soils. Soil Sci. Soc. Am. J. 49:651-657.

Palmer, C.D., and P.R. Wittbrodt. 1991. Processes affecting the remediation of chromium-contaminated sites. Environ. Health Perspect. 92:25-40.

Pettine, M., F.J. Millero, and R. Passino. 1994. Reduction of chromium (VI) with hydrogen sulfide in $\mathrm{NaCl}$ media. Mar. Chem. 46:335-344.

Proctor, D.M., B.L. Finley, M.A. Harris, D.J. Paustenbach, and D. Rabbe. 1997. Chromium in soil: Perspectives in chemistry, health, and environmental regulation. Lewis Publ., Boca Raton, FL.

Rai, D., L.E. Eary, and J.M. Zachara. 1989. Environmental chemistry of chromium. Sci. Total Environ. 86:15-23.

Robinson, R.A., and R.H. Stokes. 1959. Electrolyte solutions. Academic Press, New York.

Santschi, P., P. Hohener, G. Benoit, and M. Buchholz-ten Brink. 1990. Chemical processes at the sediment-water interface. Mar. Chem. 30:269-315.

SAS Institute. 2002. JMP Version 5.0. SAS Inst., Cary, NC.

Sedlak, D.L., and P.G. Chan. 1997. Reduction of hexavalent chromium by ferrous iron. Geochim. Cosmochim. Acta 61:2185-2192.

Seech, A.G., and E.G. Beauchamp. 1988. Denitrification in soil aggregates of different sizes. Soil Sci. Soc. Am. J. 52:1616-1621.

Smith, K.A. 1977. Soil aeration. Soil Sci. 123:284-291.
Sposito, G. 1984. The surface chemistry of soils. Oxford Univ. Press, New York.

Sturges, S.G., Jr., P. McBeth, Jr., and R.C. Pratt. 1992. Performance of soil flushing and groundwater extraction at the United Chrome Superfund site. J. Hazard. Mater. 29:59-78.

Thiele, E.W. 1939. Relation between catalytic activity and size of particle. Ind. Eng. Chem. 31:916-920.

Tokunaga, T.K., S.R. Sutton, and S. Bajt. 1994. Mapping of selenium concentrations in soil aggregates with synchrotron x-ray fluorescence microprobe. Soil Sci. 158:421-434.

Tokunaga, T.K., J. Wan, M.K. Firestone, T.C. Hazen, E. Schwartz, S.R. Sutton, and M. Newville. 2001. Chromium diffusion and reduction in soil aggregates. Environ. Sci. Technol. 35:3169-3174.

Tunlid, A., D. Ringelberg, C. Low, T.J. Phelps, and D.C. White. 1989. A micromethod for the analysis of phospholipid fatty acids from bacteria in environmental samples. J. Microbiol. Methods 10:139-153.

Weisz, P.B. 1973. Diffusion and chemical transformation. Science (Washington, DC) 179:433-440.

Wielinga, B., M.M. Mizuba, C.M. Hansel, and S. Fendorf. 2001. Iron promoted reduction of chromate by dissimilatory iron-reducing bacteria. Environ. Sci. Technol. 35:522-527.

Wilcke, W., and M. Kaupenjohann. 1998. Heavy metal distribution between soil aggregate core and surface fractions along gradients of deposition from the atmosphere. Geoderma 83:55-66.

Williams, A.G.B., and M.M. Scherer. 2001. Kinetics of Cr(VI) reduction by carbonate green rust. Environ. Sci. Technol. 35:3488-3494.

Zachara, J.M., C.C. Ainsworth, C.E. Cowan, and C.T. Resch. 1989. Adsorption of chromate by subsurface soil horizons. Soil Sci. Soc. Am. J. 53:418-428.

Zausig, J., W. Stepniewski, and R. Horn. 1993. Oxygen concentration and redox potential gradients in unsaturated model soil aggregates. Soil Sci. Soc. Am. J. 57:908-916. 